\title{
DIGNIFICACIÓN Y LIBERACIÓN DE LO HUMANO DIVERSO
}

\section{DIGNIFICATION AND LIBERATION OF THE HUMAN-DIVERSITY}

\author{
Hermann Güendel* \\ Universidad Estatal a Distancia de Costa Rica
}

Recibido: 20 de junio, 2014 • Aceptado: 16 noviembre, 2014

Resumen: A finales del siglo veinte se produjo en Costa Rica, como resultado de la implementación de políticas neoliberales, una modificación integral de las relaciones y condiciones sociales de vivencia; la relación estructural-superestructural que sostenía el escenario tradicional de cotidianidad entró entonces en declive. El viejo y sólido mundo de los costarricenses perdió sus acostumbradas certezas. La incertidumbre se apoderó de la existencia. Las centralizaciones de significados que sostenían la forma de ser, pensar y valorar hegemónicas perdieron comprensibilidad y coherencia; con esto se propició la constitución de los grupos etarios, de mujeres, indígenas, emigrantes y homosexuales en actores de un nuevo y complejo escenario de cotidianidad. Para la filosofía costarricense la aparición de estos nuevos actores y relaciones humanas propone el reto de desarrollar un nuevo tipo de hacer filosófico: una hermenéutica de las diversidades, como un enfoque que dé lugar a la configuración de un nuevo sentido común social integrador y dignificador a la vez.

Palabras clave: centralización, significado, filosofía.

Abstract: At the end of 21th Century, as result of the implementation of neoliberal policies, Costa Rica experienced an integral modification of the relations and social conditions of life; the relation structural-superstructural that supported the traditional scenario of daily life suffered a decline. The old

* Hermann Güendel cuenta con numerosos artículos de opinión publicados en el Semanario Universidad de la UCR, así como con ensayos especializados que aparecen en las revistas Espiga de la UNED, Praxis de la UNA y la Revista de Filosofía de la UCR. 
and solid world of Costa Ricans lost his certainties. Uncertainty seizes existence. The centralization of meanings that supported life, thinking and the way people values hegemonies, lost compressibility and coherence. This produced the consolidation of age groups, women, indigenous, emigrants and homosexuals as acting agents in a new scenario of daily life. For Costa Rican philosophy, the emergence of this new actors and human relations represents a challenge to develop a new type of philosophy: a hermeneutic of diversities. This new philosophy must configure a new social common sense, which integrate and dignifies people.

Keywords: centralization, meaning, philosophy.

\section{La transición a un nuevo tipo de sujeto}

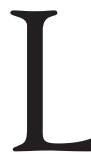

a solidez del mundo descansa en su normatividad. Más que habitar en una realidad que se sustente en sí misma, nuestra existencia transcurre dentro de una artificialidad histórica surgida de actos de centralización, que, como un sistema, coloniza nuestras formas de ser, pensar y convivir, con normatividades que desbordan el sano juicio, transformando actos de barbarie en civilizatorios, disfrazando intensiones, muchas perversas, tras el noble título de ideales.

De esta artificialidad solo cobramos conciencia por los acontecimientos que sacuden nuestra rutinaria existencia, pues el mundo está compuesto por totalitarismos epistemológicos y segmentaciones ontológicas, fragmentos diversos que dan lugar a cotidianidades disociadas, propios de sujetos diferentes que conviven dentro de los límites de marcos superestructurales de compresibilidad y reconocimiento inter-subjetivo.

En un mundo que ha perdido su solidez el ser humano pierde sus esperanzas, las relaciones de coexistencia se pervierten a tal grado que si se quiere conocer la verdad de otro es necesario pensar con malicia sus actos e intenciones. La despreocupada convivencia de goce se disipa entre el turbio aire de actitudes enfermizas. Las relaciones íntimas y filiales se trastocan en condicionamientos que nos encadenan a imposturas. La persona se transforma en un "otro" diferente, aceptable solo en su sometimiento a prejuiciosos caprichos. El amor y la amistad no constituyen un nosotros, sino una sujeción apropiadora que nos reduce a objetos sin voluntad, inteligencia o deseos propios.

Algunos, escondiéndose de la mísera incertidumbre cotidiana, se refugian en actos pasionales convulsionados por turbias e intensas incertidumbres 
de amor, desprecio, odio y aprecio. Otros, escondiéndose más de sí mismos que del mundo, prefieren el uterino refugio de imposturas fugaces de indiferencia y disimulo. Ya no nos es posible convivir con una desinteresada complacencia festiva.

La decadencia del sistema-mundo capitalista ha hecho que el ser humano pierda la capacidad de aceptar la diversidad y sus diferencias, lejos estamos de una convivencia tolerante. Pervertido el espíritu humano, el yo solo puede enfrentar sus múltiples interacciones si las reduce a representaciones aparenciales y disimulos. Interacciones pervertidas entre seres desvirtuados que no son más que frágiles representaciones de seres humanos, el resultado de no poder aceptar las humanas complejidades si no las hacemos invisibles, si no les asignamos una valoración de ser, pensar y actuar desde nuestras perversiones y prejuicios.

Como no podemos eludir lo otro -como lo hacemos con aquellas cosas sobre las que no podemos imponernos- le pasamos de largo sin brindarle ninguna importancia y le asignamos una condición representativa que evoca algún derecho que se sustituye según las convulsiones del momento.

Mas no hay derechos que al asignársenos nos conviertan en sujetos, pues no somos sujetos al recibir una acción, sino al producirla; el sujeto es tal en cuanto se constituye como actor.

El reconocimiento de la condición de ser humano no descansa en derecho alguno, sino en la vivencia colectiva de un "nosotros", en la compañía desinteresada que se celebra a través de múltiples experiencias.

Esta convivencia festiva, despreocupada complacencia que nos genera la presencia de aquellos que enriquecen con su sutil brillo la penumbra de nuestro decadente mundo, solo es posible entre aquellos que se aceptan mutuamente en su complejidad y riqueza de diversidades, pasando uno al lado del otro en una rica danza de iniciativas y actividades que enriquecen el espacio con movimiento y el tiempo con buena compañía.

Convivir con agrado entre personas solo es posible si aquello que llena los diversos lugares y momentos de la existencia cotidiana resulta celebrable, no por ser lo acostumbrado, sino por ser propio de aquel que forma, a nuestro lado, parte del nosotros. El convivir de nosotros es despreocupado.

No puede pensarse que el horizonte actual de relaciones es el único al que podemos aspirar como forma de "convivencia" cotidiana. Entre sujetos 
es posible superar la ruptura de la normatividad del mundo con la reconstrucción de un nosotros identitario que constituya un mundo mejor. Tolerar no es disimular lo que nos repugna, sino trivializar lo que nos sorprende de los que estimamos.

\section{La hipócrita danza de la cotidianidad}

La convivencia humana se ha tornado tan compleja que exige un tipo de compresibilidad simultáneamente expansiva y aleatoria, posibilitadora de una sana interacción entre sujetos y del reconocimiento de sus subjetividades.

El impacto de lo espontáneo nos aturde. Tanto lo acostumbrado como lo que es inesperado ha de ser vinculado a alguna categoría de valoración e interpretación existente dentro de un régimen de significados, para poder entender cada manifestación de las diversas identidades humanas como una identificación consciente de espacios, lugares, tiempos, momentos, sujetos y conductas.

La ruptura de aquel régimen superestructural de significados, provocada por la irrupción de nuevos actores, ha hecho que la capacidad de comprensión inter-subjetiva se pierda, a tal grado, que lo inesperado, lejos de poder aceptarse como la particularidad propia de aquel que aún no es parte del "nosotros", sea tan solo expresión repugnante de su vulgaridad, disimulable apenas en su anonimato y distancia.

Ansioso por el control de un mundo colapsado, el ser humano se ha hundido en una danza de hipócrita cotidianidad que lo lleva a centralizar tiránicamente lo que otros hacen dentro de lo que espera, desea y ordena. La diversidad se ve así agobiada por miradas de desprecio y sonrisas burlonas.

En un escenario de perversión de relaciones filiales la convivencia se ha distorsionado hasta el grado que el sujeto, para ser tratado como persona, debe ser reducido a un objeto constituido por aquello que complace a aquel que lo acepta como parte de su cotidianidad, como si la convivencia con él no fuese un simple evento, sino más bien un privilegio.

Ser lo que somos, sin guardar las conocidas normas de la apariencia -con las que, como lo dictan las buenas costumbres, hemos de comportarnos cuando recién conocemos a otro-, es una costosa prerrogativa cuyo precio es la burla, el desprecio y la soledad. 
Los regímenes superestructurales de significados son el resultado de una articulación intencional y de larga data dentro de las sociedades capitalistas. Diversidad de discursos filosóficos, políticos y religiosos, enunciados desde lugares específicos de poder y privilegio, destacaron y consolidaron conductas de diferenciación identitaria autovalidada, elevándolas al grado de usuales convenciones conductuales. Los significados superestructurales hegemónicos surgieron así de conductas de diferenciación que, en su novedad, primero fueron trivializadas como excéntricos modismos de innovadores espíritus que se abrían a la configuración de su identidad, y luego elevadas al rango de conductas de identidad consolidadas.

Antes de que cada época sea hegemonizada por una tiranía de los significados, la cotidianidad del mundo transita fugazmente por rutas de resistencia identitaria. Una dinámica de innovaciones conductuales que subsiste hasta que la experimentación con significados e identidades se ve ahogada en absolutizaciones éticas, políticas y religiosas, que, desbordando la inteligencia, disfrazan lo espontáneo con el prístino lino de lo que luego se llama virtud. El amanecer de una nueva época se ve opacado por las sombras de los prejuicios que precipita. Víctima de sus peros, el mismo ser humano enjuiciado enjuicia al otro como vulgar.

Un espíritu envilecido que se considera libre, siendo más bien esclavo de prejuicios, reduce al otro a objeto, siguiendo la ruta convencional que transita la existencia colonizada por la individualización capitalista, que impide la afirmación de lo humano en la diversidad constitutiva y diferenciadora del nosotros. La perversa rutina de intolerancia se refugia de sí misma entre los hipócritas disimulos de las "buenas costumbres".

Mas lo extraordinario para el filósofo no es esa danza de imposturas, sino la agitada turbulencia de resistencias a exclusiones y reducciones simbólicas, dentro de la que se configuran nuevos espacios alternativos de cotidianidad, nuevos escenarios de relaciones filiales en los que emergen y se consolidan significados identitarios descentralizados.

Nos hemos precipitado hacia un cambio sobre el cual no tenemos ninguna certidumbre, pero en el que los excluidos ciframos nuestras esperanzas de una alternativa post-capitalista, más que por argumento de la ciencia, por argumento de la esperanza que se valida en la certeza de que los gritos de los que están en el infierno no pueden dirigirse más que hacia el cielo. 


\section{La dignificación de lo cotidiano}

Las relaciones de cotidianidad se han vuelto más complejas, pues vivimos diariamente relaciones inter-fronterizas. Rozamos a los otros desde un nosotros que nos lleva a tratarlos a través de un prejuicioso juego de imágenes y disminuciones ónticas que invaden su anonimato, con la voluntad de controlar su incertidumbre.

Aquel, cuya presencia no podemos evadir, se resiste a nuestro disimulo; pero no a las condiciones que le imponemos como requisito para saltar más allá de un encuentro impersonal. Antes de que el otro sea reconocido como próximo, el espíritu humano, colonizado por diversas centralizaciones del pensar, ser y existir propias del capitalismo, exige su dominio a través del sometimiento a las buenas costumbres y "conductas elegantes". La categoría de sujeto se le asigna hasta entonces como prerrogativa de aquel que reconoce el derecho del otro a ser a su lado algo más que una cosa o un esclavo.

Mas no hay derechos que nos constituyan en sujetos, pues, como ya lo mencioné, no se es sujeto al recibir una acción, sino al producirla. Solo se es propiamente sujeto cuando, en condición de actor, se configura la realidad en mundo, debido a su sometimiento a la voluntad humana. El mundo es nuestra creación más elaborada, no es más que aquello que posee sentido para el ser humano dentro de él; y la vivencia se refiere a las experiencias que constituyen la cotidianidad.

La cotidianidad humana es la vivencia de múltiples experiencias disociadas. Delimitada por ellas, la interacción entre anónimos debe responder a encuentros, no de sujeción, sino de confirmación, para poder ser entendida como relación dignificante, o ser repudiada como relación que denigra.

La dignidad humana no se sustenta en su reconocimiento como sujeto de derecho. No son los derechos humanos los que nos confirman como personas. Confirmar la humanidad del otro por simple evocación de sus derechos es tan solo incluirlo, jamás incorporarlo realmente como un sujeto capaz de construir su propia realidad y configurar dentro de ella los significados que la consoliden. El ser humano se afirma a sí mismo como sujeto en la acción de resistencia contra la exclusión, la invisibilización y el silenciamiento. Nadie reconoce al actor, sino que este se impone por sí mismo.

Si el tema de la constitución del otro en ser humano se ve reducido a la condescendiente asignación de derechos humanos, el tema está ya 
agotado y la preocupación por los derechos humanos debe ser abordada de un modo alternativo.

Pobre conciencia envilecida que, en la desventura de existir vivenciando tan solo significados constituidos, olvida que los derechos no se piden, se exigen, no se dan, se arrebatan. Solo en el espíritu del rebelde lo dignificador es alternativo, y lo alternativo afirma su libertad.

La acción constitutiva del otro en ser humano trasciende su resistencia, concentrándose en el alcance de redefinición de las relaciones que provoca en esa misma resistencia. El ser humano se constituye, asimismo, como ruptura y resignificación de su realidad. El mundo tiende entonces a fragmentarse para ser colonizado por aquellos que lo habitan, no como resultado de imágenes o imposturas, sino como resultado de interacciones satisfactorias y dignificadas.

En el roce casual entre sujetos, la convivencia festiva que le es propia a los espíritus libremente despreocupados propicia una fractura en la rutinaria cotidianidad centralizada a la que estamos sometidos en el capitalismo.

Rozamos furtivos mundos diversos aún sin saberlo, pues en cada otro al que nos enfrentamos hay una identidad corporizada, no por una simple ocurrencia que tal vez nos parezca extravagante, sino por orgullosa y despreocupada evidencia de que se es alguien solo cuando se ha sido incorporado en un mundo diferenciado.

En el roce despreocupado la complejidad de nuestra cotidianidad nos lleva a un transitar inter-fronterizo que nos aproxima a seres humanos dignificados por la satisfacción del reconocimiento mutuo. Este es un tipo alternativo de nosotros que libera de imposturas a la humana convivencia, despreciando disimulos al confirmar la trivialidad de aquello que nos sorprende en quienes, siendo para nosotros parte de lo que somos, se incorporan a nuestro mundo para enriquecerlo como una continua danza de festivas improvisaciones, bellas ocurrencias e inesperadas manifestaciones de amor y esperanza.

\section{Actores alternativos y fragmentaciones de la cotidianidad}

El roce casual con el otro nos lleva a rozar su mundo. Por ello, el encuentro entre distintos sujetos es un excitante transitar furtivo. Somos tránsfugas que burlan con su encuentro fronteras identitarias compuestas por valoraciones e interpretaciones diversas. 
La diversidad de los otros nos lleva a trascender la rutina del nosotros. Enfrentado a lo que le es incomprensible, nuestro espíritu no puede refugiarse en sí mismo, pues ha perdido la coherencia de sus certidumbres. Acorralado por lo que no puede evadir, se abre a una nueva forma de comprensibilidad que se expande más allá de las regiones de lo que le es seguro. Escapando al profundo aturdimiento que engendra lo inusitado, asocia aleatoriamente significados emergentes con realidades inusitadas. Los espacios de encuentro casual tienden, de esta manera, a ser más que lugares de roce fortuito. Pasan a ser momentos de aceptación de las diferencias. Por ello, en las comunidades diferenciadas -las colectividades- la resistencia adquiere la forma de pasión orgullosa. Ahí donde la resistencia de unos engendró subsistencia al disimulo se le ha dado cabida a la coexistencia de todos. El sujeto desemboca en un productor de nuevas prácticas y expectativas colectivas descentralizadas.

Constituye, de este modo, nuevas contra-normatividades y afirmaciones magníficas de la diversidad humana. Solo en condición de actor el ser humano logra liberarse y consolidar un nuevo tipo de libertad, democratizar la vivencia diaria e incorporar la diversidad como criterio fundante de un nuevo significado de tolerancia, configurando un tipo distinto de sociedad y sociabilidad; una sociedad democratizada constituyente de un mundo diversificado.

La diversidad como realidad humana no puede incluirse, sino incorporarse. El otro no puede reivindicarse con el simple placebo de recibir derechos, pues al recibirlos se le están restando aquellos aspectos de su multidimensionalidad que no son institucionalizables. Incluir sin incorporar es excluir simbólicamente; esto es lo que hemos hecho por tantos años con los homosexuales, los emigrantes y los indígenas. Solo en la unidad de lo diverso habita lo humano. Solo en la fragmentación del mundo es posible repensar su verdadera unidad.

Nuevos tipos de nosotros han irrumpido en el mundo y lo han diversificado. Estos no son reducibles a categorías tradicionales, pues sus definiciones identitarias han surgido de respuestas novedosas a la exclusión física y la denigración simbólica. Los nuevos sujetos son producto de su propia resistencia, no de su reivindicación jurídica. Ni el homosexual, ni el inmigrante, ni el indígena, ni ningún otro de los nuevos nosotros requiere un mesías libertador que venga en su auxilio. 
La psicología que sustenta el liderazgo desaparece cuando las condiciones que hacen necesario a un líder no desembocan en depositar la confianza en alguno para que encause las diversas voluntades, sino en confiar en sí mismos como sinergia promotora de la afirmación de nuevas y distintas posibilidades.

Existe así un alcance novedoso y liberador en las actuales fracturas de la rutina, que limitaba la cotidianidad a interacciones centralizadas por significados excluyentes e invisibilizadores de lo diverso. En su fragmentación los diversos lugares y momentos son colonizados por actores que los constituyen.

La sociedad civil se descentra no como resultado de un proyecto, sino como una lateralidad de vivencias que se autovalidan y consolidan como prácticas identitarias que no se refugian en imposturas, ni requieren de justificación alguna para ser disfrutadas. La fragmentación de la cotidianidad da lugar a la gestación de una alternatividad descentralizada post-capitalista, que se gestiona dentro de colectividades como modos de ser y pensar identitarios particulares. Esa alternatividad no constituye un proyecto institucionalizado, no aspira a desplazar los significados superestructurales existentes con nuevas formas de ser, pensar y actuar que sean prerrogativas de todo ser humano; solamente aspira a lograr el encuentro de los diferenciados fuera de aquellos viejos refugios que constituían antros de simulación, ya fueran subterráneos o desterritorializados, bares de homosexuales o parques de iglesias colonizados por emigrantes.

No es por los derechos de los sujetos, sino por los alcances de la resistencia de los actores que se provoca una nueva época de humanismo en la que se consolida lo humano por medio de la incorporación de lo diverso.

La resignificación no crea nueva realidades, sino valoraciones; redefine los impactos, las cotidianidades y las posibilidades valorativas del mundo, provocando un modo diverso de constitución de realidades históricas. La multiplicidad de experiencias que constituye nuestra cotidianidad se enriquece con el encuentro y el reconocimiento de lo diverso como su contenido más humano y, por ello, más bello.

\section{Un nuevo tipo de mundo y de historia}

El mundo se precipita a su resignificación. Transitamos del colapso del sistema- mundo neoliberal a un nuevo momento de humanismo en el que 
la conceptualización sobre el sujeto se traslada del derecho a la condición ontológica de significador de realidades.

El ser humano reconfigura ahora su mundo, democratizándolo por medio de la diversificación. Las viejas centralizaciones que lo redujeron a una expresión homogénea no se sostienen sin arduas justificaciones y represiones. Creadas por el sistema mundo capitalista a través de la colonización del ser, pensar y hacer, las reducciones ónticas, estéticas y éticas que sostienen el dominio - no como simple relación de poder, sino como categoría de gobernabilidad de lo diverso- ya no significan nada, ya no tienen ningún sentido.

La realidad histórica aparece diversificada en multiplicidad de lugares y momentos que se colonizan con valoraciones e interpretaciones propias de quienes la habitan. Las relaciones sociales se fragmentan como una nueva forma de unidad. El ser humano dignificado pasa entre distintos mundos de un modo transcognitivo, como si fuera un tránsfuga de fronteras; su cotidianidad actual se ha tornado compleja por ser un roce inter-fronterizo. A través de un nuevo tipo de compresibilidad, expansiva y aleatoria, el reconocimiento de la complejidad nos ha abierto al libre tránsito cotidiano entre significados, actores y mundos diversos.

Las diversas formas de vinculación cotidiana se arbitran por complejos entrecruzamientos de significados y relaciones físicas. Son estas vecindades con los diversos otros las que, por encima de las relaciones de poder jurídicas y simbólicas constituidas, hacen de nuestra cotidianidad un escenario de aproximación a nuevas formas de relaciones íntimas y filiales, cuyos alcances enriquecen nuestra existencia, aunque no permitan asegurar, en este momento, si la faz de esta nueva época post-capitalista será al menos próxima a lo que se imagina.

En el mundo centralizado capitalista las relaciones de intimación resultaban de la reducción del ser humano a un ser vaciado de novedades. La cotidianidad se concebía como rutinaria existencia familiarizada; se trataba de una segura región de certidumbres que tanta paz traía a la conciencia desventurada. Fuera de ella, las relaciones casuales nos colocaban frente a otro que, en su anonimato, podía despertar alguna pasión, pero que, ausente de sentido para nosotros, no era más que una simple imagen estética, un ser vaciado de identidad. 
A través de la imposición de su presencia, que no se puede obviar, esa imagen cobraba para nosotros resistencia, nuestra indolente conciencia se refugiaba entonces de las complicaciones recurriendo a la evocación de derechos. El otro era ahora un cierto tipo de sujeto iluminado salvíficamente del anonimato, un ser desgarrado por derechos. Sujeto incompleto, pues lo era no en ruptura, sino en complaciente condescendencia. Este sujeto desgarrado por derechos solo podía regocijarse en su condición reconocida, no era pues sujeto, sino inocencia complacida, silencio comprometido. El escenario de cotidianidad centralizada lo había constituido en otro tipo de objeto, el constituido por recibir derechos. El indígena podía ahora vender su miseria, el gay abrir su bar, el migrante recibir atención médica gratuita.

Si el ser humano irrumpe en el mundo solo como poseedor de identidad institucionalizada, su integración difícilmente puede superar la fragilidad del modismo; se mantiene tan solo en el rango de una inclusión que desemboca en la ruptura de este ser diversificado por uno re-homogenizado. Hablar de un ser humano, cuando no hay un único modo de ser humano, sino una diversidad, es un juego del lenguaje que obstaculiza la comprensión sensata de las diferencias como nueva forma de unidad.

Hoy me es posible afirmar que la condición de ser humano se confirma más allá de su institucionalización. El sujeto rompe con esa designación, anhelando la vida desprecia la subsistencia piadosa y la existencia indolente. El ser humano se ha proyectado más allá de los derechos humanos, sus distintas generaciones ya son insuficientes, pues, elevado por encima del rango de sujeto, el ser humano es actor.

Las nuevas realidades que configura este otro sujeto, este actor orgulloso, coexisten en su fragmentación y se rozan cotidianamente. Son realidades corporizadas en seres humanos que reflejan su identidad, que han dejado de esconderse de ella, pues en multiplicidad de lugares y momentos de reconocimiento dignificado se han precipitado modos compresibles de convivencia festiva, despreocupada y, con ello, tan humanizada, que seducen a cualquier espíritu que, seguro de sí mismo, pueda vivir rozando el mundo del otro a través de su piel, sin provocarse acaso más que una furtiva sonrisa sin necesidad de justificación alguna. 


\section{Fenomenología del reconocimiento del otro}

La irrupción de un actor precipita la constitución de múltiples sujetos. Más que a un individuo, el actor refiere a una voz que crea significados y constituye identidad, resignificando la vivencia, proclamando y constituyendo la dignidad de múltiples personas. Es así multiplicidad de conciencias cuyas voluntades no están complacidas, cuyos silencios no están comprometidos, pues la inclusión le es insuficiente y la incorporación le es aún distante.

El actor reorganiza lugares y momentos. Se impone y los coloniza con prácticas constitutivas de escenarios de vinculación, en ellos puede despojarse del anonimato al que lo reducía aquella exclusión física y simbólica que lo llevaba a avergonzarse de sí mismo.

En un escenario distinto de reconocimiento y aproximación despreocupada las relaciones humanas no resultan impersonales, sino filiales, inmediatas, pues en lo cotidiano nadie convive con millones de seres humanos, sino que -con intención- toca a unas cuantas personas y, casualmente, se roza con unas pocas decenas.

Sobrevivir a la grosera existencia que padece una época de incertidumbres como la actual solo le es posible a nuestra desventurada conciencia dentro de aquellas regiones de la realidad histórica que resultan acostumbradas, seguras, simbólicamente al menos, pues las hemos colonizado figurativamente con nuestra recurrente presencia.

Las incertidumbres nos provocan desconfianza, la presencia de un otro anónimo nos provoca recelo. Simplemente escapamos de su virtual amenaza a través del subterfugio del disimulo y la furtiva mirada.

Su realidad humana no nos interesa, en su anonimato resulta excluido de nuestra capacidad de reconocimiento, de nuestro interés y de nuestros sentimientos. Pero este otro incierto es persona más allá de nuestros cierres simbólico-identitarios, y como tal resiste nuestro desprecio y nos habla. Supera nuestra evasión con su presencia, se convierte en alguien en ese lugar y momento en el que nos resultaba indiferente. Sin tal osadía su existencia se oculta entre los bastidores del desprecio. Incluido por su inevitable presencia en nuestro mundo, no se encuentra incorporado más que a lo casual, a aquel mero roce que no aceptamos y que podemos disminuir con un gesto. 
Somos conscientes de la existencia del otro, no por su identidad, sino por sus acontecimientos. Sus movimientos y arrebatos nos llevan a fijarnos en él e incluirlo, con desprecio por su vulgaridad, dentro de nuestra región acostumbrada de realidad. Lo sometemos a una asimilación excluyente que lo deforma, pero que nos permite rechazar su incorporación a nuestro mundo; el otro ya no es una amenaza anónima, ahora es el borracho necio o el sucio adicto, la loca o el migrante...de nuestro barrio.

La inclusión del otro diverso solo es inobjetable si su presencia se hace recurrente en los lugares y momentos que hemos colonizado simbólicamente con nuestra simple presencia, y que por ello nos es acostumbrada y no aceptamos simplemente abandonar.

Ese otro corporaliza la exclusión a la que se le ha sometido, es persona que trasciende la condición de sujeto a través de su resistencia a distintos cierres simbólicos. Su dignidad no se fundamenta en lo que se le otorga, sino en lo que arrebata al invadir un centralizado mundo de prácticas y valoraciones identitarias diferenciables, constitutivas de fronteras.

Su resistencia agota la lógica de exclusión y centralización, impone formas de racionalidad diferenciada que precipitan la incorporación de la diversidad a nuestra cotidianidad. La irrupción del actor nos ha llevado a otras posibilidades de significado, de relación y encuentro en lugres y momentos inevitablemente comunes. Nos lleva a descentralizar las formas de ser, pensar, valorar y constituir la realidad, a pensar en una nueva utopía: la de la época del humanismo absoluto de la historia.

\section{Historicidad del reconocimiento del otro}

Con desdén pasamos al lado del niño de la calle, desviando nuestra mirada de su ruinosa presencia, apresuramos el paso escapando de su reclamo dignificador. Nos hemos hundido en una despreocupación impersonal que asesina al prójimo y desvirtúa nuestro enojo ante la injusticia que se hace visible en rostros anónimos. Las condiciones estructurales de la irracionalidad capitalista neoliberal hacen que el otro, antes de ser reconocido como alguien, sea percibido con recelo y desconfianza.

Las condiciones epistemológicas hegemónicas en el sistema-mundo capitalista han pervertido las posibilidades de reconocimiento a través de 
la modificación del contexto de relaciones de cotidianidad con la mezquina actitud de procurar ampliar los nichos de reproducción del capital hacia lo público, lo humano y lo natural.

La vivencia cotidiana padece de anomia, víctima de una presión distorsionante que pervierte las posibilidades de relaciones de reconocimiento filiales. Una crisis integral que va más allá de lo que cualquier espíritu despierto puede tolerar. Su conciencia se rebela entonces ante la disolución del horizonte del mundo, desemboca en resistencia y articulación de nuevos espacios reivindicatorios de nuestra alienada dignidad. El espíritu despierto aborda de modo diferente el tema del reconocimiento y se precipita a la redefinición de una alternatividad utópica y postneoliberal. Pasa así de su consideración como sobreviviente del genocidio, refugiado, huérfano de guerra, a pensarlo de modo diferente como migrante y excluido.

Se ha saltado del tema de la diversidad de situaciones del humano al tema de la diversidad identitaria como criterio de inclusión integral. La discusión sobre la incorporación de los otros trasciende las figuras jurídicas, se amplía a lo ético, cultural, étnico, generacional y de género, articulando la controversia bajo la categoría de ruptura con las condiciones centralizadas de ser, pensar, poder y existir, a las que se encuentra sometido el ser humano dentro de la sociedad capitalista.

Los condicionamientos superestructurales del modo de pensar hegemónico en la sociedad capitalista neoliberal solo posibilitan la aproximación al tema del reconocimiento de los diversos otros desde dos lugares de enunciación deficitarios: su reducción a formas jurídicas logocéntricas, unidimensionales y deformantes; y la reducción de los distintos modos de pensar y las formas prácticas a referentes eurocentrados de cultura.

Con ello las posibilidades del reconocimiento solo se dan desde las condiciones estructurales que asignan el estatus de la persona de modo disciplinario y represivo, adecuado sin duda a un modelo de gobernabilidad configurado sobre la base de prerrogativas, intereses privados falsamente planteados como sociales y exclusiones. El otro es disminuido estética, moral e intelectualmente quedando fuera de ellas. Antes de ser sujeto es objeto de nuestro recelo, disimulo, desconfianza y desprecio, antes de ser persona es alguien que no me interesa. 
El régimen superestructural de exclusión capitalista solo ha provocado el silenciamiento y la disminución simbólica de lo diverso. Una sociedad que estructuralmente sostiene conductas impersonales es superestructuralmente excluyente. Un nuevo escenario de reconocimiento e integración asume la formulación de procedimientos de integración como anticriterios de gobernabilidad clasista, o sea, como formas de articulación práctica e identitaria de racionalidades no centralizadas en el logos y en referentes estructurales eurocivilizatorios.

El otro en su diversidad constituye fronteras identitarias a partir de múltiples formas de proceder de racionalidad diferenciada: resistencia, voluntad, imaginación, esperanza, experiencia mística y diálogo. Desde su resistencia restaura su dignidad y favorece la supervivencia del excluido, imponiendo y reconociendo la diversidad como condición de cotidianidad y autenticidad identitaria. Hemos desembocado en un horizonte más amplio, un nuevo período de la historia que aspira a superar lo impersonal y despectivo.

\section{Fronteras identitarias y cierres simbólicos}

El filósofo tiene la tarea de pensar sobre todo en su momento. Criatura de la noche, recorre el mundo rozando las sombras que restan de los que han perdido el significado de sus vidas, percibiendo, en la aurora, el contorno transparente de aquellos que se esfuerzan por resignificarse como personas. El espíritu inquieto proclama entonces que el ocaso de una época da paso al amanecer a otra nueva. La filosofía actual es un discurso de la transición entre épocas.

Estamos, sin embargo, en un tipo diferente de amanecer, no el de la acostumbrada rutina que agota toda esperanza, sino el de un contexto diferente de relaciones humanas, tanto alternativas como reivindicadoras. Las conciencias despiertan inconformes...los indignados forjan formas diversas de salida de las centralizaciones en el ser, existir, valorar y pensar que en el capitalismo neoliberal han reducido estructuralmente las posibilidades de filiación humana a formas virtuales y ficticias.

El capitalismo neoliberal dio paso a una sociedad de rivalidades, competidores egoístas que recurren a la vigilancia, la despreocupación y el desprecio como formas de afirmación de sí mismos. Esta es la única sociedad en la historia donde la conducta impersonal es estructural. El alma bella se ve aquí condenada a formas de comunicación virtual: de voz sin rostro, de 
palabra sin voz, presencia bidimensional...ese tipo de filiaciones que es predilecto para alguien incapaz de ser con el otro un "nosotros". Una sociedad estructuralmente impersonal es superestructuralmente excluyente.

Por ello, la asociación de significados que constituye cualquier identidad solo puede comportarse como la lógica de conjuntos, y construir "hacia fuera" fronteras identitarias que "desde afuera" constituyan cierres simbólicos, ya sea estéticos, éticos o culturales particulares a una forma de existir diferenciable.

Estos cierres dan lugar y se sustentan en enunciaciones que institucionalizan, por vía jurídica o no, de carácter comunitario, colectivo o, bien, sociopolítico, como los que aparecen en el seno de las relaciones complejas entre la sociedad política y la sociedad civil, dando lugar todas ellas a prácticas represivas que se manifiestan en exclusiones, distorsiones y diferenciaciones simbólicas de actos, actitudes, valoraciones e interpretaciones de la realidad histórica. Lo superestructural se transforma en estructural, y, a su vez, da lugar a contenidos superestructurales.

Las identidades poseen entonces lugares de enunciación epistemológica, o modos de pensar desde los que la percepción del otro se simplifica, limitando las posibilidades de reconocimiento igualitario a formas de diferenciación excluyente que operacionalizan los cierres simbólicos y les asignan sedes espacio-temporales propias, donde la forma de hablar, actuar y vestir resulta pertinente y agradable. Inevitablemente, en el capitalismo las identidades crean exclusiones de un modo tan cerrado que incluso el excluido excluye.

Por otra parte, al visibilizarse en formas de existir, actuar y hablar diferenciables, las identidades constituidas posibilitan la ejecución de relaciones de poder horizontales y verticales, distorsionadoras y reductivas del otro al anonimato; el sujeto cae entonces en una despreocupación impersonal por la vulgar subsistencia de aquel que no reconoce.

La dificultad de reconocer al otro en las condiciones de centralización del capitalismo radica estructuralmente en aquella condición superestructural (lógica de conjuntos) que sustenta la vivencia cotidiana solo dentro de fronteras de significado identitario. El ser humano es encerrado así en formas de ser y existir integralmente deficitarias, pues imposibilitan la integración del excluido a la cotidianidad, a no ser que se incluya a sí mismo a través de la resistencia y la autovisibilización impositiva. 
Las posibilidades del reconocimiento y la filiación se han dirigido hacia ámbitos externos a nuestra cotidianidad acostumbrada, pues dentro de ella solo se sustentan distanciamientos seguros y roces impersonales, un tipo de relación con el otro que no perdura en nuestra alma más de lo que perdura una imagen fugaz en nuestra memoria, así, no se elimina la "amenaza" del otro, tan solo se disminuye.

El capitalismo neoliberal es integralmente deficitario de condiciones de dignificación del excluido, de ese otro que somos nosotros. La dignificación humana se gesta a sí misma en la conformación de ese otro mundo mejor posible que se vislumbra en el amanecer: un mundo post-neoliberal.

\section{Libertad y dignidad}

La resistencia de quien sobrevive dignifica su identidad. La aproximación a la libertad se gesta en los diversos actos de resistencia del otro contra las denigraciones éticas, estéticas y culturales que sustentan su exclusión física y simbólica de nuestro mundo.

El otro crea su mundo para sobrevivir al nuestro. Su reivindicación como ser humano no radica simplemente en incluir su presencia en nuestro mundo, reconociéndolo desde su posición de resistencia. Su dignificación no es prerrogativa nuestra, sino incorporación de su realidad como cotidianidad nuestra.

El otro no es libre por concesión jurídica, sino por dominio. Resiste las condiciones estructurales de centralización reductiva más allá de nuestros disimulos. Es digno antes de provocarnos la necesidad de disimularlo. Lo que encuentra en juego no es su libertad, sino su capacidad de vivir más allá de su mundo. La dignidad se convierte así en un tema de reivindicación ontológica de su mundo, más que un tema de discusión ética o antropológica en el nuestro.

La dignificación del ser humano transita por la consolidación del reconocimiento de su diversidad. La diversidad de prácticas, valoraciones y relaciones humanas han de imponerse por sí mismas, por encima de la centralización jurídica política del sistema-mundo actual y decadente, para que puedan enriquecer nuestra cotidianidad con espacios de reconocimiento y prácticas de vinculación satisfactorias y cambiantes. 
Dentro de cada mundo se viven formas de exclusión dirigidas a lo que se encuentra fuera del tipo de realidad que lo constituye. La diversidad de los mundos y de los seres humanos dentro de ellos no es lo que impone un nuevo régimen de convivencia tolerante. Es la interrelación de los mundos y los sujetos lo que promueve la aparición de formas diversas de reconocimiento auto-asignado. Se trata del posicionamiento de un nuevo modo de ser humano dentro de la realidad histórica, de manera que se pueda disfrutar de la evidencia descubierta de la identidad del otro, sin recelo o vergüenza, como compañía que nos enriquece por ser agradable y sacar nuestra cotidianidad de la grosera rutina.

Dentro de cada mundo la identidad se valida hasta la vivencia gozosa por medio de modos de actuar, interpretar, relacionarse y verse diferenciables, consolidados y satisfactorios. Esas diferenciaciones identitarias no dependen de la excentricidad, o de los esfuerzos exaltados de diferenciación; sino de criterios comunitarios, o bien colectivos, que emergen de las prácticas de vinculación gratificante.

Pretender ser alguien sin un "nosotros" no da lugar a un reconocimiento desde fuera y hacia dentro, sino a un aislamiento que hace más compleja la exclusión que padece, pues, impuesto por sí mismo, solo desemboca en resentimiento, soledad, amargura y desprecio hacia los demás.

Un ser orgulloso de sí mismo se abre sin reserva y sin temor al rostro de lo diverso, hasta donde logre trivializar la sorpresiva danza de sus actitudes, algunas tal vez irreverentes. La impertinencia del otro se soporta hasta donde lo sostiene el agrado que sentimos por él. La impertinencia del amigo, del amado y del reconocido no es impertinencia, sino arrebato inesperado. Sin embargo, ese mismo arrebato, proveniente de quien está más allá de nosotros, solo es sinónimo de su vulgaridad, tan burda como la nuestra, pero que, tan solo por ser suya, no nos es posible trivializar. Debido a las formas de proceder conductuales que se desprenden de la lógica de las identidades no se puede convivir satisfactoriamente con aquellos con los que solo convivimos inevitablemente.

Las diferencias identitarias constituyen mundos específicos de filiación que sostienen la bulliciosa danza de quienes amamos y estimados con relaciones de acompañamiento solidario, aunque no necesariamente incondicional, pues cuando un acto del "nosotros" sale de su frontera nos distanciamos de quién amábamos hasta el resentimiento. 
Las definiciones identitarias que constituyen fronteras de filiación hacen de nuestras relaciones íntimas y filiales relaciones permanentemente frágiles. Tan frágiles que el recatado cuido de nuestro modo de hablar, actuar y vestir nos puede resultar incómodo.

El aroma de la dignidad nos lleva entonces a buscar ser de otro modo, uno que no nos agobie, pues ansiamos el goce irreverente de ser nuestro ser mismo. Nuestra dignidad consiste en nuestra autenticidad identitaria.

Así, por dignidad, rompemos con definiciones de significados y sentidos que nos resultan insatisfactorios ante la ausencia de asidero histórico y efectividad. Modos de ser, identidades aparenciales, propios solo de aquellos cuya profundidad solo se mantiene en la superficie de su piel.

El espíritu se angustia y, no teniendo refugio en la evasión, ${ }^{1}$ se avoca inconforme a explorar mundos de filiación diferidos, modos de ser alternativos, para configurar identidades de modo sintético e intencional. La persona se convierte en un monstruo irreconocible para quienes eran un "nosotros" con él. Pero este monstruo no espanta, solo se distancia.

Su ser monstruoso posee una forma diferente de belleza, a veces trágica y siempre riesgosa. Escapando del viejo mundo y su decadencia, sin tener a la vista algún otro nuevo, se desespera en la búsqueda de una autenticidad que no entiende, ya que la piensa en la ausencia de los otros, pretendiendo ser alguien sin ellos. Su desesperada búsqueda de una autenticidad identitaria solo desemboca en la degradación de quien pretendía dignificarse. El contenido se pierde, la persona se transforma en puro contorno; ¿se divierte? Sí, tal vez hasta el extremo goce, éxtasis sublime en el que se pierde la conciencia, se aliena haciéndose daño, en cada bocanada de risas se le escapa la opción de confirmar su vida.

No se posee una identidad reconocible como resultado de una ocurrencia, excentricidad o simple creatividad que improvisa. Las identidades se articulan por medio de discriminaciones y vinculaciones de significado, tan sensatamente estructuradas que incluso poseen una estética en sus vínculos,

1 En La fenomenología del espíritu (1987) Hegel señaló que la conciencia desventurada cuenta con cuatro rutas de evasión: la actitud piadosa que nos refugia en la religión; la desaforada actitud laboriosa que nos agota; la festiva actitud del que vive solo el momento y el lugar en el que esta; y el suicidio, que no es para él una alternativa, sino la negación de la única salida de la desventura, la confirmación del dominio humano del mundo que ha creado, la libertad. 
un buen gusto o elegancia que les es pertinente, y con las cuales podemos intencionalmente jugar.

No poseemos un solo rostro, sino tantos como las exigencias de cada mundo nos obliguen a guardar impostura, no tal vez para ser aceptados, sino tan solo para poder movernos y sobrevivir dentro de ellos.

Esa estética interna en la articulación de significados no implica que se dé lugar a una definición sobre la estética de quien corporaliza una identidad. Esta estética de las corporalidades es más bien una definición de sentido que se desprende de los significados articulados dentro de una identidad reconocible, poseyendo, entonces, condiciones específicas que no son lógicas, sino aparenciales, o sea, propias de moda o costumbre .

Más bien, esa estética en la articulación lógica es propiamente la secuencia reconocible de asociaciones, aleatorias o no, de aquella lógica de conjuntos que da lugar a la construcción de identidades de un modo articulado. Por ello, podemos movernos de una identidad a otra, o de un mundo a otro, sin perder coherencia o elegante pertinencia, según el escenario de relaciones de reconocimiento en el que nos encontremos. Poseyendo una identidad somos capaces de impostar muchas.

Lo hacemos intuitivamente. Tras un pequeño atisbo damos seguimiento, afortunado o no, a la lógica de esa identidad. Nos comportamos como los otros esperan que lo hagamos dentro de su mundo, aun cuando no sea el nuestro. Lo hacemos de modo exquisito incluso, guardando bajo el término de buenas costumbres la estética que posee esa lógica identitaria, sin que por ello se garantice que nuestra apariencia sea la más celebrable o al menos la adecuada.

Quien como mujer define su modo de ser madre desecha de su integralidad aquello que le impide verse en la intimidad sin provocarse vergüenza. No se puede ser una madre despreocupada o promiscua, aun cuando pueda perfectamente serse una mujer así. No se es alguien de modo despreocupado. Sin duda se goza de ser alguien de ese modo, pero no puede serse así, pues la actitud licenciosa nos saca de las fronteras de nuestra identidad.

Igual puede decirse de cuando, ahogado por la insuficiencia de las identidades constituidas, el espíritu decide explorar alternatividades identitarias. No hay posibilidades de ser alguien de modo precipitado, pretendiendo ser mágicamente feliz. Se quiere disfrutar de la vida, no solo escapar de la cotidiana pesadilla de las exclusiones y disimulos. 
La dignidad identitaria, esa que exige nuestro espíritu inconforme, nos obliga a ser alguien diferenciable a plena luz del día, no en la oscuridad o en la bruma. Ser persona es más que ser una figura borrosa, aunque bella, como el contorno de una bailarina entre la niebla.

La dignidad del excluido (al final todos lo somos de un modo u otro) se constituye como la acción liberadora que lo confirma como alguien en el mundo que constituye con quienes los reconocen y le permiten dignificarse.

No se es alguien en ausencia de otros, aun en nuestra soledad somos lo que con otros correspondería que fuésemos como nosotros. Por estar solo en mi oficina no dejo de ser hombre, migrante, heterosexual, si es que esa es mi identidad, no mi impostura. Sin esta solidez identitaria en mi soledad estaría desnudo ante mí mismo, mi intimidad desembocaría en angustia.

Toda vivencia identitaria, aun cuando sea alternativa, resulta siempre de una síntesis de determinaciones complejas, institucionales, culturales y jurídicas. Las superestructuras de una sociedad dan lugar a actos estructurales que les otorgan contenido a las definiciones superestructurales mismas, ya sea ratificando sus significados y sentidos o resemantizándolos. Por ello se vive poco, se existe demasiado; el goce del flautista termina con la última nota que sale de su instrumento.

Aun cuando nuestra necesidad de escapar de alguna identidad insatisfactoria promueva la exploración identitaria, una vez que esta se sustente en sí misma, con vivencias dignificadas dentro de un mundo de filiaciones satisfactorias, terminará esclavizando. La nueva forma de pensar y ser crea sus imperativos para permitir vivencias cotidianas continuamente satisfactorias y pertinentes.

No se puede ser en el caos, sino en una diferenciación reconocible, normada. En esto se basa la solidez de los distintos mundos que son habitables por cada identidad diferenciada. Dentro de una misma realidad histórica las diversas identidades que se presentan crean fragmentaciones tanto epistemológicas como ontológicas, estéticas y éticas, que contienen un mundo que les es propio, aun cuando jurídicamente no sea su propiedad.

La propiedad privada se desapropia al habitarla. El lugar donde nos encontramos y somos sin limitaciones e imposturas es nuestro sin importar que no seamos sus dueños. Una identidad dignificada se adueña del lugar y del momento que habita, pues ahí la diferencia se realiza como goce filial, 
porque las relaciones de filiación e intimación nos dan esa confianza que solo vivimos cuando el viraje de alguna experiencia nos lleva a convivir despreocupados, moviéndonos sin timidez o permiso.

La dignidad identitaria se vivencia como libertad de ser lo que soy sin avergonzarme de ello. Es un tipo de libertad novedosa, no es una condición política amparada en una norma jurídica, tampoco en una condición ontológica del ser humano, sino en la vivencia de la seguridad identitaria de no ser excluido u objeto de burla, desprecio o disimulo. Esta vivencia solo puede sustentarse en el dominio del mundo en el que soy, no en tanto que lo controlo o gobierno, sino en tanto que lo habito sin restricciones e imposturas.

El logro más significativo de esta nueva forma de ser libremente un humano diferente es la reconstrucción de la realidad histórica fuera de la centralización invisibilizadora de lo diverso, como síntesis de fragmentaciones cuyas fronteras se besan a través de definiciones heterogéneas de ser, pensar y actuar.

En la alborada de una nueva época de la historia, se puede ser alguien distinto de un modo dignificado, ser alguien que goza de su condición humana diversa y diferenciada. Solo hay un modo de vivenciar el placer y el goce: el despreocupado convivir del nosotros. El acto de dignificación ha resultado ser un acto de libertad: fragmentar la realidad histórica centralizada para abrirnos al roce inter-fronterizo, ser lo que soy, desde mi nosotros, con lo que los otros son desde su propio nosotros.

\section{Bibliografía}

Casirer, E. (1982). Antropología filosófica. México: Fondo de Cultura Económica.

De Sousa Santos, B. (2000). Crítica de la razón indolente. Volumen 1. Bilbao: Desclee.

De Sousa Santos, B. (2006). Conocimiento y transformación social: por una ecología de saberes. Brasil: Hileia.

Houtard, F. (2006). Derecho, socio biodiversidad y soberanía. Brasil: Hileia.

Fernández-Vásquez, R. (1979). La razón orgánica. Heredia: EUNA.

Fromm, E. (1974). El arte de amar. Buenos Aires: Paidós.

Hegel, G.W. F. (1987). La fenomenología del espíritu. México: Fondo de Cultura Económica. Olarte, T. (1974). El ser y el hombre. San Pedro, Costa Rica: Efa.

Soto-Badilla , J. (1986). Hacia un concepto de persona. San José: EUCR.

Taylor, C. (1993). La política del reconocimiento. México: Fondo De Cultura Económica. Trias, E. (1987). Los límites del mundo. Madrid: Ariel. 